\title{
Mild impairment of neuro-otological function in early treated congenital hypothyroidism
}

\author{
S C Bellman, A Davies, P W Fuggle, D B Grant, I Smith
}

\begin{abstract}
Pure tone audiometry, tympanometry, acoustic stapedial reflex thresholds (ASRTs), and auditory evoked brain stem responses (AEBRs) were carried out in 38 children with early treated congenital hypothyroidism aged 10-12 years, together with tests of vestibular function (electronystagraphy, rotational, and caloric tests). Sensorineural hearing loss with thresholds of greater than $15 \mathrm{~dB}$ was detected in 18 children (10 at $8 \mathrm{kHz}$ only); only two children had more than $40 \mathrm{~dB}$ hearing loss, each in one ear. Raised ASRTs were found in eight children and two children had abnormal AEBRs. Of the 29 children tested, 12 had an abnormality of vestibular function. Although not significant at the $5 \%$ level, there was a tendency for the abnormalities to be more prevalent and severe in the children with more severe hypothyroidism, as judged by pretreatment plasma thyroxine. It is concluded that (i) mild abnormality of hearing is still common in children with congenital hypothyroidism despite early treatment but this is much less severe than that found before neonatal screening and (ii) mild abnormalities of vestibular function may be common in early treated congenital hypothyroidism. (Arch Dis Child 1996; 74: 215-218)
\end{abstract}

Keywords: congenital hypothyroidism, neuro-otological function.

It has long been recognised that congenital hypothyroidism can be associated with hearing impairment. Early studies concentrated on endemic hypothyroidism caused by low iodine intake and Pendred's syndrome, a rare recessively inherited condition in which a defect in thyroid hormone biosynthesis is associated with hearing loss and the Mondini-type deformity of the cochlea. A few studies have been carried out on children with sporadic congenital hypothyroidism born before widespread introduction of neonatal screening and these have shown severe bilateral impairment of hearing in $20-36 \%$ of cases. ${ }^{1-3} \mathrm{We}$ are aware of only two studies in early treated congenital hypothyroidism, 45 both of which showed increased prevalence of mildly impaired hearing. Similarly, there is little information on vestibular function in sporadic congenital hypothyroidism, apart from that published by Sato et al showing abnormal vestibular function in 10 out of 13 subjects with late treated congenital hypothyroidism. ${ }^{6}$
The present study was carried out to record the prevalence of audiovestibular problems in a cohort of children born in 1978-81 with early treated congenital hypothyroidism diagnosed by screening. Hearing was assessed by pure tone audiometry, together with measurements of acoustic stapedial reflex thresholds (ASRTs), and auditory evoked brain stem responses (AEBRs). Vestibular function was studied by carrying out electronystagmography (ENG), vestibular ocular reflex testing, and caloric testing. In this paper we describe our findings which indicate that mild impairment of hearing and vestibular function may still occur in children with congenital hypothyroidism despite early diagnosis and treatment.

\section{Patients and methods}

PATIENTS

The nine boys and 29 girls who agreed to participate in this study and who had tests of neuro-otological function between the ages of 10 and 12 years are members of a larger cohort of children with congenital hypothyroidism born in 1978-81 who have been followed up to the age of 10 years. ${ }^{7-9}$ The sex distribution, severity of hypothyroidism (judged by median pretreatment plasma thyroxine $(40 \mathrm{nmol} / \mathrm{l})$, and thyroid stimulating hormone $(292 \mathrm{mU} / \mathrm{l})$ ), as well as median age at start of treatment (28 days) were similar in the children who were tested and the 40 other members of the cohort who did not participate in the study.

Tests were carried out over a period of three years, using the same equipment. The procedures were lengthy and demanding and only 29 children were able to complete every component of all the tests; details of patient numbers for each test are given in tables 1 and 2. The study was approved by the local ethics committee and families were given a written description of the test procedures, followed by further verbal explanations when necessary.

\section{METHODS}

\section{Clinical assessment}

Tests at the start of the examination included otoscopy, gait assessment with Unterberger and heel/toe walking tests, eye patch cover tests to uncover latent strabismus, and examination for spontaneous nystagmus, pursuit, and saccade eye movements.

\section{Audiological assessment}

The following procedures were carried out'to assess hearing.

(A) Pure tone audiometry using a Kamplex 
Table 1 Number (\%) of normal and abnormal hearing tests in 76 ears tested in 38 children with congenital hypothyroidism. The results are grouped by severity of hypothyroidism (severe: pretreatment plasma thyroxine 40 nmoll or below; less severe; pretreatment plasma thyroxine over 40 nmoll)

\begin{tabular}{lccc}
\hline & \multicolumn{3}{l}{ Children with congenital hypothyroidism } \\
\cline { 2 - 4 } & Severe & Less severe & Total \\
\hline (A) No of ears tested & $(n=42)$ & $(n=34)$ & $(n=76)$ \\
Normal hearing: threshold $15 \mathrm{~dB}$ or less & $24(57)$ & $25(73)$ & $49(64)$ \\
Mild hearing loss: threshold $16-40 \mathrm{~dB}$ & $9(21)$ & $5(15)$ & $14(18)$ \\
$8 \mathrm{kHz}$ only & $8(19)$ & $3(9)$ & $11(14)$ \\
$0.5-8 \mathrm{kHz}$ & $1(2)$ & $1(3)$ & $2(3)$ \\
Moderate hearing loss: threshold above $40 \mathrm{~dB}$ & $(n=21)$ & $(n=17)$ & $(n=38)$ \\
(B) No of children tested & $13(62)$ & $11(65)$ & $24(63)$ \\
Normal hearing: threshold $15 \mathrm{~dB}$ or less & $2(10)$ & $4(23)$ & $6(16)$ \\
Mild hearing loss: threshold $16-40 \mathrm{~dB}$ & $6(28)$ & $2(11)$ & $8(21)$ \\
8 kHz only & & & \\
$0.5-8 \mathrm{kHz}$ & & &
\end{tabular}

AC5 audiometer and TDH 39 headphones. Departmental normal values were obtained in 96 healthy children aged 8-10 years. Normal hearing was taken as threshold level of 15 dBHTL or better at all frequencies from $0.5-8 \cdot 0 \mathrm{kHz}$.

(B) Tympanometry and ASRT using a Grayson Stadler GSI33 tympanometer. Normal middle ear pressure was taken as +50 to $-150 \mathrm{daPa}$. Acoustic reflex thresholds were measured to $0 \cdot 5,1 \cdot 2$, and $4 \mathrm{kHz}$ stimuli, presented ipsilaterally. Departmental normal values obtained in 36 healthy children aged 8-10 years were used. An abnormal response was recorded if the ASRT was greater than 105 $\mathrm{dB}$ at two or more adjacent frequencies when hearing was better than $60 \mathrm{~dB}$. This is similar to the range established in adults. ${ }^{10}$

(C) $A E B R s$ were recorded using a Medelec sensor system with click stimuli of $80 \mathrm{~dB}$ hearing level presented at 20 clicks/second and alternating polarity through standard TDH39 headphones. The average of 1024 sweeps was taken and latencies of waves $\mathrm{I}$ and $\mathrm{V}$ were analysed. These were considered abnormal if conduction time exceeded 2 SD from the age related departmental norms obtained in 36 healthy children aged 8-10 years.

\section{Vestibular tests}

The following procedures were carried out to assess vestibular function. Departmental normal values were obtained in 36 healthy children aged 8-10 years for all these tests.

(A) ENG was performed using a DC recorder to document: (i) spontaneous nystagmus with the slow phase velocity greater than $5 \%$ sec; (ii) saccade and pursuit movements; and (iii) and optokinetic nystagmus.

(B) Vestibular ocular reflex testing was carried out with ENG recording of eye movements and: (i) clockwise and counterclockwise rotation in an $\mathrm{AD} 9$ rotating chair which was set in motion with an initial acceleration of $10 \% \mathrm{sec}$ and reached a final velocity of $120 \% \mathrm{sec}$, followed by deceleration to $0 \% \mathrm{sec}$ in $1 \mathrm{sec}$. An abnormal response was taken as directional preponderance greater than $20 \%$. (ii) Sinusoidal movement in an AD9 chair with frequency of $0.5 \mathrm{~Hz}$ and recording at maximal velocities rising from $9 \cdot 4 \% \mathrm{sec}$ to $37.6 \% \mathrm{sec}$. An abnormal response was taken as absent nystagmus at a velocity of $18.8 \% \mathrm{sec}$ and directional preponderance greater than $20 \%$ in either direction.

(C) Caloric testing using the standard Hallpike and Fitzgerald technique with irrigation with water at $44^{\circ}$ and $30^{\circ}$ for $30 \mathrm{sec}$. Duration of response was recorded by direct vision, first with fixation, and then with abolition of fixation using Frenzle glasses to confirm normal enhancement of response. An abnormal response was taken as canal paresis greater than $15 \%$ or directional preponderance greater than $25 \%$, that is, outside 2 SD for departmental norms.

\section{STATISTICAL ANALYSIS}

We have previously reported that outcome for intelligence at 3,5 , and 10 years was less satisfactory in the children with severe hypothyroidism, ${ }^{7-9}$ and one aim of the study was to ascertain whether severity of hypothyroidism at diagnosis also affected outcome for neurootological function. Accordingly, the children were divided into two groups: 21 with pretreatment thyroxine concentrations of $40 \mathrm{nmol} / /$ or below (severe) and 17 with initial thyroxine over $40 \mathrm{nmol} / 1$ (less severe) ${ }^{8} \chi^{2}$ Tests were used to assess the significance of differences between the groups. A $t$ test was used to compare mean lengths in a standing broad jump test at 5 years in the children with and without abnormal ASRTs.

\section{Results}

CLINICAL ASSESSMENT

Otoscopy was normal in all but one child who had evidence of middle ear dysfunction. Of the 35 children tested, strabismus was present in four (all from the severely hypothyroid group) and in these cases ENG was made separately across each eye. Abnormal gait was found in 13 of the 31 children tested (table 2), seven on the Unterberger test, five on heel/toe walking, and one on both tests.

\section{AUDIOMETRY AND TYMPANOMETRY}

These tests were carried out in all the children. Three children had slightly negative pressures of -155 to $-200 \mathrm{daPa}$ on tympanometry; two had normal hearing and one had a mixed hearing loss.

Some sensorineural hearing loss was present

Table 2 Number (\%) of abnormal test results for balance, vestibular function, $A S R T$, and $A E B R$ in 38 children with congenital hypothyroidism. Values are numbers of children tested in each group with the percentage of abnormal results in parentheses

\begin{tabular}{llll}
\hline & \multicolumn{3}{c}{ Children with congenital hypothyroidism } \\
\cline { 2 - 4 } $\begin{array}{l}\text { Type of test } \\
\text { and result }\end{array}$ & $\begin{array}{l}\text { Severe } \\
(n=21)\end{array}$ & $\begin{array}{l}\text { Less severe } \\
(n=17)\end{array}$ & $\begin{array}{l}\text { Total } \\
(n=38)\end{array}$ \\
\hline (A) Balance: clinical examination \\
$\begin{array}{l}7 / 17(41) \\
\text { (B) Abnormal }\end{array}$ & $6 / 15(40)$ & $13 / 32(41)$ \\
$\begin{array}{l}\text { Vestibular function tests } \\
\text { (C) Abnormal ASRT }\end{array}$ & $9 / 15(60)$ & $3 / 14(21)$ & $12 / 29(41)$ \\
(D) Abnormal AEBR (No of ears tested) & $6 / 18(33)$ & $2 / 17(18)$ & $8 / 35(23)$ \\
Abnormal & $1 / 40(3)$ & $1 / 32(3)$ & $2 / 72(3)$ \\
\hline
\end{tabular}


in 18 children (table 1 ). Ten had loss at $8 \mathrm{kHz}$ only, the thresholds ranging from $20-45 \mathrm{~dB}$, and this was bilateral in three cases. In the children with an additional hearing loss at the other frequencies tested, thresholds were averaged over the range $0.5-8 \mathrm{kHz}$ for each ear; the results classified by the number of ears tested are also shown in table 1. Only two ears (in two children) had average thresholds greater than $40 \mathrm{~dB}$, three ears had average thresholds between $20-40 \mathrm{~dB}$, and six average thresholds below $20 \mathrm{~dB}$.

ASRT

ASRTs were measured in 35 children. Raised thresholds were found in eight (table 2), one child also having pathological delay. Five of these children had evidence of sensorineural hearing loss, four at $8 \mathrm{kHz}$ only; in the other child hearing loss was mild and in none of these cases were the raised hearing thresholds sufficient to account for the abnormal ASRTs. Of the remaining three children with abnormal ASRTs, hearing was normal in the affected ear but one had tinnitus in the opposite ear.

\section{AEBRS}

These were recorded in response to ipsilateral stimulation in 36 children (table 2). The mean (SD) I-V latencies were $3.91(0.34) \mathrm{ms}$ and $3.93(0.28) \mathrm{ms}$, respectively, for the right and left ears and two children were judged to have prolonged I-V latencies above the upper normal departmental limit of $4.37 \mathrm{~ms}$. One had hearing loss in the opposite ear (balance was not tested), the other had normal hearing in both ears but impaired balance. Neither child had abnormal vestibular or ASRT results.

\section{VESTIBULAR FUNCTION}

Of the 29 children who completed all the tests, 12 had some abnormality (table 2). Four had absent caloric responses, seven had abnormal responses to rotational/sinusoidal movement, and one had abnormal responses to both tests.

RELATION TO SEVERITY OF HYPOTHYROIDISM The results for the children with pretreatment thyroxine concentrations of $40 \mathrm{nmol} / 1$ or less, and those with values above $40 \mathrm{nmol} / 1$ are shown in tables 1 and 2 . While there was a trend for the children with more severe hypothyroidism to show increased hearing loss, increased impairment of ASRT, and more frequent abnormalities on vestibular function tests, these differences were not of statistical significance.

RELATION TO TESTS OF MOTOR FUNCTION AT 5 YEARS

The eight children with one or more abnormal ASRT results did significantly less well on the standing broad jump test, one of the procedures used to assess motor function at 5 years; their mean (SD) jump length was $57 \cdot 6(12 \cdot 4)$ $\mathrm{cm}$ as opposed to $75 \cdot 6(17 \cdot 3) \mathrm{cm}$ achieved by the 25 children with normal ASRTs $(t=2 \cdot 71$; $\mathrm{p}<0.02)$. No other significant associations were found between neuro-otological function and motor skills at 5 years.

\section{Discussion}

The results of this study indicate that children with congenital hypothyroidism have some impairment of hearing despite early treatment and that a significant number may have thresholds greater than $15 \mathrm{~dB}$, a level of hearing which can be a significant handicap for spoken speech. ${ }^{11}$ While we do not have matched controls for our study, the results can be compared with age related departmental norms and with those obtained in other studies in normal children. For example, Buren et al screened 172 normal 10 year olds and found that only $5 \%$ had hearing thresholds of $20 \mathrm{~dB}$ or greater at $8 \mathrm{kHz}$, as compared with $47 \%$ of the children in our study. ${ }^{12}$

Our results are similar to those of Francois $e t$ al in 42 children with early treated congenital hypothyroidism; 12 had sensorineural hearing loss of $20-50 \mathrm{~dB}$ at $8 \mathrm{kHz}$ and two had mild bilateral hearing loss at conversational frequencies. ${ }^{4}$ Again, Vatovec et al tested hearing in 63 children with congenital hypothyroidism and found impaired hearing in nine. ${ }^{5}$

In comparison with earlier studies carried out before the introduction of screening for congenital hypothyroidism, the prevalence of impaired hearing appears unchanged. For example, Crifo et al found that over $50 \%$ of their subjects had some degree of sensorineural hearing impairment, ${ }^{2}$ compared with $47 \%$ in our study and Debruyne et al found bilateral sensorineural hearing impairment in $20 \%$ of their cases, ${ }^{3}$ compared with $23 \%$ of patients in our study. However, unlike these earlier studies, none of our cases showed evidence of severely impaired hearing with thresholds of 50 $\mathrm{dB}$ or greater in the better ear. Only two (5\%) children had bilateral hearing loss with a better ear threshold of 20-40 dB, one of whom needed amplification. This compares with an incidence of $13 \%$ with an average threshold worse than $20 \mathrm{~dB}$ in the better ear and $9 \%$ with thresholds greater than $41 \mathrm{~dB}$ reported by Debruyne et al. ${ }^{3}$ These results, together with our own findings, suggest that the effects of congenital hypothyroidism on hearing can be largely prevented by early treatment, even though relatively minor degrees of hearing impairment which are of little clinical consequence can still be documented.

In the present study ASRT and AEBRs were carried out to identify any abnormalities of the auditory/neural pathways. Abnormalities of ASRT can result from pathology affecting any part of the reflex system and Lutman showed that middle ear disorders with a $20 \mathrm{~dB}$ air-bone gap account for about half the abnormalities of ASRT. ${ }^{13}$ However, in our study the only child with any air-bone gap had normal ASRTs and AEBRs and in none of the children with raised or absent ASRTs could this be explained by hearing impairment. Abnormal ASRT and 
decay are seen with neural lesions and eight $(23 \%)$ of our patients showed this pattern of abnormality which is consistent with neural pathology. Dussault and Hébert studied evoked potentials in 34 children with early treated congenital hypothyroidism and reported that seven showed a prolonged interval between waves I-V. ${ }^{14}$ They considered that their findings could reflect high frequency hearing loss but as the subjects were neonates the actual hearing thresholds were unknown. Their results are generally similar to our own findings of abnormal evoked responses in two of the 36 children tested.

Sato et al investigated vestibular function in 13 patients with congenital hypothyroidism and found that five had peripheral vestibular disorders and five had cerebellovestibular disorders. ${ }^{6}$ Our results indicate that vestibular function may still be impaired in congenital hypothyroidism despite early treatment, in that almost half the children tested showed an abnormality. In all cases this was a peripheral vestibular abnormality.

Impaired coordination was very common in children with congenital hypothyroidism born before introduction of screening. ${ }^{15}$ In the present subjects, Fuggle et al reported that motor coordination was impaired at the age of 5 years despite early treatment. ${ }^{7}$ We were able to demonstrate that the subjects with abnormal ASRTs performed significantly less well on a test of motor function carried out at 5 years of age (the standing broad jump), suggesting that impaired motor performance may have been related to abnormal development of neural pathways.

In conclusion, we have shown that minor impairment of hearing is common in children with congenital hypothyroidism despite early treatment, although the severity of hearing loss is much less when compared with studies carried out before introduction of screening. In addition, we have shown abnormalities of peripheral audiovestibular function in several of our patients; the abnormal ASRTs correlated with previous impairment of gross motor performance. The study provides further evidence that neurological impairment of some degree persists in subjects with congenital hypothyroidism despite early treatment.

We thank the paediatricians who collaborated in this study and the patients and families who participated in the tests. The work was supported by the Medical Research Council and the Join Academic Board of Great Ormond Street Hospital for Children NHS Trust and the Institute of Child Health.

1 Rubinstein M, Rubenstein C, Theodor R. Hearing dysfunction associated with sporadic hypothyroidism. Annals of Otology 1974; 83: 814-9.

2 Crifo S, Lazzari R, Salabe GB, Arnaldi D, Gagliardi M, Maragoni F. A retrospective study of audiological function in a group of hypothyroid patients. Int $\mathcal{f}$ Pediat Otorhinolaryngol 1980; 2: 347-55.

3 Debruyne F, Vanderscheuren-Lodeweycks M, Bastijns P. Hearing in congenital hypothyroidism. Audiology 1983; 22: 404-9.

4 Francois M, Bonfils P, Leger J, Czernichow P, Narcy P. Role of congenital hypothyroidism in hearing loss in children. $\mathcal{F}$ Pediatr 1994; 124: 444-6.

5 Vatovec J, Krzisnik C, Cerneic S, Zargi M. Auditory findings in children with congenital hypothyroidism. In: Schoonhover R, Kapteyn TS, de Laat J, eds. Proceedings of European Conference on Audiology. 19-23 March 1995: European

6 Sato T, Ishiguro C, Watanabe Y, Mizukoshi K Quantitative analysis of cerebello-vestibular function in congenital hypothyroidism. Acta Paediatr fpn 1987; 29: 121-9.

7 Fuggle PW, Grant DB, Smith I, Murphy G. Intelligence, motor skills and behaviour at 5 years in early-treated congenital hypothyroidism. Eur $\mathcal{F}$ Pediatr 1991; 150: 570-4.

8 Murphy G, Hulse JA, Jackson D, et al. Early treated hypothyoidism: development at 3 years. Arch Dis Child 1986; 61: 761-5.

9 Simons WF, Fuggle PW, Grant DB, Smith I. Intellectual development at 10 years in children with early treated congenital hypothyroidism. Arch Dis Child 1994; 71: 232-4.

10 Cohen M, Prasher D. Defining the relationship between cochlear hearing loss and acoustic reflex thresholds. Scand Audiol 1992; 21: 225-38.

11 Lutman ME, Brown EJ, Coles RRA. Self reported disability and handicap in the population in relation to pure-tone threshold, age, sex and type of hearing loss. $B r \mathcal{f}$ Audio 1987; 21: 45-58.

12 Buren M, Solem BS, Laukli E. Threshold of hearing $(0.125-20 \mathrm{kHz})$ in children and youngsters. Br $\mathcal{F}$ Audiol 1992; 26: 23-32.

13 Lutman ME. The relationship between acoustic reflex threshold and air-bone gap. Br f Audiol 1984; 18: 223-9.

14 Dussault JH, Hébert R. Potentiels évoqués auditifs chez les hypothyroïdiens congénitaux. Arch Fr Pediatr 1987; 44: 707-8.

15 MacFaul R, Dorner S, Brett EM, Grant DB. Neurological abnormalities in patients treated for hypothyroidism from early life. Arch Dis Child 1978; 53: 611-7. 